\title{
Don Sebastián de Colán y Pariña y sus ancestros: caciques de dos pueblos de la costa del corregimiento de Piura (s. XVI-XVII)
}

Don Sebastián de Colán y Pariña et ses ancêtres: caciques de deux villages indiens de la côte du corregimiento de Piura (XVI-XVII siècles)

Don Sebastián de Colán y Pariñas and his ancestors: caciques of two Indian villages on the coast of the corregimiento of Piura (XVI-XVIIth centuries)

Jorge Pável Elías Lequernaqué

\section{(2) OpenEdition}

Journals

Edición electrónica

URL: http://journals.openedition.org/bifea/3375

DOI: 10.4000/bifea.3375

ISSN: 2076-5827

\section{Editor}

Institut Français d'Études Andines

\section{Edición impresa}

Fecha de publicación: 1 abril 2008

Paginación: 151-161

ISSN: 0303-7495

Referencia electrónica

Jorge Pável Elías Lequernaqué, « Don Sebastián de Colán y Pariña y sus ancestros: caciques de dos pueblos de la costa del corregimiento de Piura (s. XVI-XVII) », Bulletin de l'Institut français d'études andines [En línea], 37 (1) | 2008, Publicado el 01 octubre 2008, consultado el 26 noviembre 2020. URL : http://journals.openedition.org/bifea/3375 ; DOI : https://doi.org/10.4000/bifea.3375

Les contenus du Bulletin de l'Institut français d'études andines sont mis à disposition selon les termes de la licence Creative Commons Attribution - Pas d'Utilisation Commerciale - Pas de Modification 4.0 International. 


\title{
Don Sebastián de Colán y Pariña y sus ancestros: caciques de dos pueblos de la costa del corregimiento de Piura (s. XVI-XVII)
}

\author{
Jorge Pável Elías Lequernaqué*
}

\section{Resumen}

El cacique jugó un doble papel importante dentro de la sociedad virreinal que se gestó luego de la Conquista, frente a su propio pueblo y ante la autoridad virreinal a la que le debía rendir cuentas periódicamente. El presente trabajo aborda un estudio preliminar sobre la actuación de los caciques del pueblo de Colán (que se ubica en la costa litoral del actual departamento de Piura en el Perú) durante los siglos XVI y XVII en los ámbitos social y económico.

Palabras clave: Piura, Colán, Catacaos, Pariña, caciques, encomienda, tributo

\section{Don Sebastián de Colán y Pariña et ses ancêtres: caciques de deux villages indiens de la côte du corregimiento de Piura (XVI-XVII è siècles)}

\section{Résumé}

Le cacique joua un important rôle dual au sein de la société coloniale qui se mit en place après la conquête : d'une part face à ses propres administrés, et de l'autre, face à l'autorité relevant du vice-roi à laquelle il devait rendre des comptes périodiquement. Ce travail rend compte d'une étude préliminaire portant sur le comportement des caciques du village de Colán (situé sur le littoral de I'actuel département de Piura au Pérou) durant les XVI et XVIIè siècles, dans le domaine social et économique.

Mots clés : Piura, Colán, Catacaos, Pariña, caciques, encomienda, tributo 


\title{
Don Sebastián de Colán y Pariñas and his ancestors: caciques of two Indian villages on the coast of the corregimiento of Piura (XVI-XVIIth centuries)
}

\begin{abstract}
The cacique played a dual role in the viceregal society that was created after the Spanish conquest, mediating between his own population and viceregal officials who demanded a periodic accounting. The present work is a preliminary study of the social and economic behavior of the caciques of the population of Colan (an area situated on the north coast of the modern Department of Piura, Peru) during the 16 th and 17 th centuries.
\end{abstract}

Key words: Piura, Colán, Catacaos, Pariña, caciques, encomienda, tribute

El 29 de diciembre de 1693, estando muy enfermo del cuerpo, pero sano en su juicio y entendimiento, el sargento mayor Sebastián de Colán y Pariña ${ }^{1}$ (indígena físicamente, pero mestizo en su formación cultural) otorgaba su testamento, postrado en su casa del pueblo de San Juan del Valle de Catacaos. Lo acompañaban, además del escribano y testigos, su esposa Ana de Mechato y sus queridas hijas Rosa y Catalina (ARP, Corregimientos: leg. 18, exp. 331)2.

A pesar del gran dolor físico que le aquejaba y la prisa por dejar ordenado su testamento, tuvo tiempo de reflexionar sobre lo que había sido su vida, y la gran responsabilidad y papel que le había tocado desempeñar como cacique y señor de parcialidades ubicadas en dos de los más importantes pueblos indígenas de la costa del corregimiento de Piura en la segunda mitad del siglo XVII: Colán, en el pueblo San Lucas de Colán y Pariña en el de San Juan del Valle de Catacaos.

Pasó por su mente todo lo que él había vivido, y todo lo que su padre Francisco le había contado de sus ancestros, también caciques, del pueblo de Colán. No llegó a hablarle de los caciques de tiempos prehispánicos, pues la memoria de ellos, para esta época ya se había perdido.

\section{LOS CACIQUES DE COLÁN: SU HERENCIA PATERNA}

Colán (él lo sabía muy bien) era la parcialidad originaria — considerada de «los primeros pobladores»—- más importante del pueblo San Lucas de Colán. Además, este pueblo estaba conformado por las parcialidades de Malacas, Guaura, Nizama, Vitonera y Camacho,

1 Actualmente existe un distrito en la provincia piurana de Talara que se denomina Pariñas, es además la capital provincial. En el presente trabajo vamos a utilizar el vocablo Pariña pues es la forma antigua de denominar a la encomienda y también era la denominación de sus gobernantes (caciques). Con el transcurrir de los siglos, a este vocablo, por razones lingüísticas, se le agregó la «S».

2 El traslado del testamento se encuenta inserto en el expediente de un juicio que en dicho año inició la viuda del cacique doña Ana Mechato contra los indios Juan de Salas, Juan Erun y don Domingo Nisama por una cantidad de pesos que le debían a su esposo. El testamento se encuentra completo y contiene información sobre las actividades privadas y públicas del cacique. La importancia del mismo radica en que es uno de los dos únicos testamentos completos de autoridades indígenas en el corregimiento de Piura de los siglos XVI y XVII que se han podido encontrar hasta el momento. 
quienes eran pescadores y agricultores. En esta conformación, también existían las parcialidades forasteras consideradas como «advenedizas» o «mitmas». Una de ellas fue la de Camacho, llamadas así por

«haver sido en los principios de un fulano de Camacho su encomendero, [y] para conocerlos y dividirlos y que no se mezclasen con los naturales del dicho pueblo los nombraban yndios de Camacho» (ARP, Corregimientos: leg. 12, exp. 196).

Otro grupo de mitmas fueron los miembros de la parcialidad de Guaura, quienes eran pescadores, figurando ya como asentados en Colán desde tiempos de Pedro de la Gasca (Rostworowski, 1982: 510).

Estos dos tipos de grupos se encontraban visitados y empadronados juntos, tenían sus caciques, pero el principal de todos y el encargado de cobrar la totalidad del tributo de todas las parcialidades era el de Colán. De esta primacía de Colán sobre las demás era consciente don Sebastián y lo tuvo muy en cuenta en sus actividades, oficiales y no oficiales, a lo largo de su vida.

Recordó que su padre le habló de doña Luisa, la capullana de Colán, quien gobernó el cacicazgo antes de las reducciones toledanas, junto a don Juan de Colán — probablemente su esposo (AGl, Contratación: 198, N 16; 210, N 6)—3. Fue, según pudo concluir, una mujer de una personalidad fuerte que gobernó a su pueblo y tuvo tiempo de entrar a relacionarse con los encomenderos, curas y corregidores de Piura, aunque de detalles de su gobierno no pudo ya acordarse.

Luego recordó a don Juan Yunchere, hijo de la capullana, quien accedió al gobierno a la muerte de su madre. Él debió haber sido el cacique que estuvo presente en el gobierno de su pueblo en el tiempo de las reducciones que realizó en el corregimiento Bernardino de Loayza, siguiendo órdenes expresas del virrey Francisco de Toledo entre los años de 1572 y 1573. Luego de la misma, el padrón dejó establecido para la parcialidad de Colán 196 personas repartidas de la siguiente manera: 51 indios tributarios (que incluía a casados, viudos y solteros de 18 a 50 años), 3 indios viejos de más de 50 años de edad (exentos por tanto del pago de tributos y obligaciones de mita), 43 indios «mossos» menores de 17 años y 99 mujeres de todas las edades y estados. Una vez excluido el cacique, quedaron 50 indios tributarios expéditos para el pago del tributo y el trabajo mitero. Desde los años 60 de ese siglo XVI, su encomendero fue Rodrigo Méndez.

El tributo total a pagar a su encomendero ascendió a 200 pesos ensayados anuales, repartidos de la siguiente manera: 156 pesos y 2 tomines en plata (moneda), 56 tomines en 5000 tollos$^{4}$ (cada ciento valuado en 6 tomines de plata) y en 100 aves de Castilla (gallinas, valuadas cada una en 6 granos). Individualmente, le tocaba a cada indio pagar en total 4 pesos divididos de la siguiente manera: 3 pesos un tomín en plata y los 7 tomines restantes en 100 tollos y dos aves de Castilla (ARP, Corregimientos: leg. 8, exp. 118)5.

Eran excelentes pescadores, de ahí que la mayor parte del tributo en especie que debían pagar era en tollos. Contaban para esta actividad con pequeños palos de balsas y redes (ARP, Corregimientos: leg. 8, exp. 118). En general, se habían ganado buena fama como indios

3 Para mayores referencias de principios del siglo XVII sobre esta capullana de Colán se puede ver en AGN (Derecho indiano: leg. 31, cuad. 627).

4 El tollo es un pez muy apreciado en toda la costa norte del Perú. Desde tiempos prehispánicos, los indígenas que habitaban las zonas costeras se dedicaban a su extracción y luego lo intercambiaban con alimentos agrícolas que eran cultivados por los agricultores de los valles. Con la conquista estos indígenas pasaron a tributar una parte en pescado y el resto en monetario. El tollo para poder conservarse se salaba y era comercializado por los indígenas y encomenderos llegando a venderse incluso en la capital virreinal. Para el proceso de salado del pescado, los caciques aprovechaban las salinas que estaban cercanas al pueblo de Colán.

5 En este documento hay un traslado de la visita hecha por Bernardino de Loayza. 
balseros y pescadores que servían muy fielmente a la Real Armada de su Majestad en todo lo que se ofreciera. No solamente en el puerto de Paita y demás caletas del corregimiento, sino que incluso iban con ellos más al norte, a puertos y caletas de la Audiencia de Quito como Chandui y Guayaquil.

También quedaron ordenados y regulados los trabajos obligatorios que los tributarios del pueblo debían realizar en forma de mita. La principal fue el abastecimiento de agua dulce (que traían desde el río Chira, cuya desembocadura se ubicaba muy cerca del pueblo al norte) y leña para los vecinos del puerto de Paita, comerciantes y pasajeros que llegaban a dicho puerto. Para esta ocupación estaban previstos 20 indios. También se contempló la mita del traslado de productos y otros elementos del Rey y de comerciantes particulares en sus balsas, a las naves o a tierra, según el caso; para lo cual estaban previstos de 14 indios del pueblo.

Estas actividades desarrolladas por los indígenas fueron muy importantes para la Corona y ellos eran conscientes de ello. Basándose en esto, recurrían continuamente al Rey, con peticiones diversas, buscando ciertos privilegios no reconocidos a los demás indígenas del corregimiento. La Corona siempre reconoció a estos indios el «mucho y buen trabajo que realizan en el navío de la Real Armada y de las demás del comercio de particulares que dan en el puerto de Paita, y lo importante de su asistencia en él» (ARP, Corregimientos: leg. 8, exp. 116). Por este motivo recibieron concesiones especiales que no gozaban los demás pueblos del corregimiento como por ejemplo, el que las autoridades del corregimiento no ocupen a los indios de Colán en otras actividades ni mitas ajenas a las señaladas por el padrón y visita toledana.

A principios del siglo XVII, don Juan continuaba vivo, pero como se encontraba ya viejo y achacoso, había dejado el cargo y gobierno efectivo del cacicazgo a su hijo don Luis de Colán, desde años antes. Debió de morir en esos inicios de siglo. En un documento notarial de 1602 figura como cacique de la parcialidad Colán y su hijo como cacique y gobernador del pueblo de Catacaos, presentando una petición, junto con los demás caciques del pueblo de Colán y del pueblo de Paita. A partir de entonces, ya no se le vuelve a mencionar más como cacique, por lo que suponemos que debió morir (ARP, Notarial Colonia: protoc. 53, fol. 144v).

Don Luis de Colán continuó con el gobierno del pueblo y parcialidad de Colán, desarrollando a la par una intensa y gran actividad como comerciante y ganadero, realizando transacciones no solamente dentro del corregimiento, sino también desenvolviéndose y actuando fuera de él: tanto en Saña y Chiclayo, como en corregimientos y lugares pertenecientes a la Audiencia de Quito (Guayaquil, Loja, Zaruma, Cuenca, la isla de la Puná, Bracamoros y hasta en la gobernación de Salinas). Su testamento del 18 de marzo de 1622 nos da a conocer datos precisos sobre esta intensa actividad (Rostworowski, 1982).

Había estado casado legítimamente con doña María, india principal del puerto de Paita, con la que no había tenido descendencia legítima alguna. Sí declara tener hijos ilegítimos o bastardos como se les solía llamar en muchas indias del común en Colán y Catacaos. Es importante este dato, pues nos permite apreciar las relaciones exogámicas que practicó la élite indígena de Colán y que será practicada también por don Sebastián, su nieto. Luis continúa este tipo de enlace y relación social, mediante su matrimonio con una india principal del pueblo de Paita y al parecer también con la de Sechura, pues tenía un nieto suyo, Pheliz, quien era hijo de uno de sus hijos ilegítimos, Juan de Colán, que estaba casado con Isabel Temocha, cacica principal del repartimiento de Sechura. 
Al morir don Luis, poco después de testar, entró a gobernar el cacicazgo de Colán su hermano Domingo, tal y como lo había establecido el testamento. Este jefe étnico continuó desarrollando algunas de las actividades que su antecesor había desarrollado. Además se va a dedicar también a la explotación y comercio de la sal, aprovechando de las salinas que se encontraban cercanas al pueblo de Colán. Este cacique tiene que afrontar momentos difíciles respecto al pago de tributo que debían realizar sus indígenas, por eso se puede explicar que en diferentes momentos de su gobierno aparezca vendiendo algunas de las casas que su hermano poseía en el puerto de Paita y numerosas cabezas de ganado para ayudar a pagar el tributo faltante del pueblo. Igual, tuvo un gobierno que se prolongó por un poco más de veinte años, encontrándose aún en diciembre de 1642, haciendo tratos y conciertos con un vecino encomendero de Guayaquil, Francisco Gutiérrez Calderón, para venderle 300 fanegas de sal (ARP, Notarial Colonia: leg. 14, protoc. 11).

A diferencia de su hermano sí dejó hijos legítimos, con los cuales continuó la tradición de «utilizarlos», mediante las relaciones exogámicas, para ampliar la red de relaciones sociales y económicas con élites indígenas de otros pueblos costeños del corregimiento. Así por ejemplo, a uno de ellos, Bartolomé lo había casado con Luisa Melchora, india que era la heredera de doña María, capullana de la parcialidad de Paita en el pueblo indígena del mismo nombre.

Pero la relación más importante es la que obtuvo del matrimonio de su hijo mayor, y su sucesor en el cacicazgo, Sancho, al casarlo con la única hija de don Francisco de Pariña el viejo, cacique de la parcialidad de Pariña, que había sido reducida en el pueblo de Catacaos, Ilamada Isabel de Pariña y que era su legítima sucesora, pues Francisco Pariña el mozo, su hermano, había muerto antes6. En este caso al morir muy pronto doña Isabel, asumió el gobierno de Pariña, Sancho — su marido y abuelo de Sebastián-. Muerto Domingo de Colán, hacia 1643-1644, asume también el gobierno de Colán, pasando a denominarse don Sancho de Colán y Pariña, que luego fue asumido también por sus sucesores.

Sancho no tuvo un gobierno prolongado, murió en el mes de abril de 1649. Los últimos días los pasó atendido por su segunda esposa, doña Francisca Canapai, cacica de la parcialidad de Narigualá, reducida en el pueblo de Catacaos. Su legítimo sucesor fue su hijo Francisco de Colán y Pariñas, a quien el corregidor de Piura, Pedro de Balladares, le dio la posesión del cargo de cacique el 24 de mayo de 1649 (ARP, Corregimientos: leg. 33, exp. 692).

Este acceso al gobierno de dos parcialidades de pueblos indígenas diferentes había resultado muy beneficioso para estos caciques. Mayor número de tributarios y mano de obra que les servía no solamente para incrementar el tributo a percibir, sino también para beneficiarse del trabajo de sus indígenas en su provecho personal, en sus diferentes y variados negocios y granjerías (trabajo en sus tierras como agricultores o pastores por ejemplo), o negociando esta mano de obra, generalmente con las autoridades de la ciudad, curas o encomenderos, a cambio no solamente de dinero, sino también de favores personales. De todo esto estaba enterado Sebastián, no solamente como ya lo dijimos, por los relatos de su padre, sino también porque él lo había vivido y lo había puesto en práctica. Pero así como su padre le había hablado de parte de la historia del pueblo de Colán, su madre, María de La Chira y su abuelo Carlos de La Chira (también cacique del pueblo de Catacaos, pero de la parcialidad de La Chira) habían alimentado su niñez y juventud con los relatos y actuación desempeñada por sus ancestros maternos como caciques principales de las parcialidades del pueblo de Catacaos.

6 Ya para el siglo XVII se puede hablar de una sucesión legítima al estilo occidental, es decir importa la primogenitura, recaiga ésta en el varón o en la mujer. Ya se ha ido perdiendo, para esta época, la forma de sucesión andina, en este caso la imperante en los cacicazgos costeños del norte del Perú actual. 


\section{LOS CACIQUES DE PARIÑA Y LA CHIRA: SU HERENCIA MATERNA}

Pariña era un cacicazgo ubicado, al momento de la llegada del gobernador Pizarro en aquel ya lejano 1532, en el litoral costeño, dedicándose sus habitantes tanto a las faenas de pesca como a la recolección de mariscos. Para complementar su alimentación debieron de haber realizado labores de intercambio de productos con cacicazgos de agricultores y ganaderos que habitaban los alrededores del río de La Chira. Es de suponer que el intercambio se extendió a otros sitios más lejanos, tanto del norte como del sur de la franja costera.

Para la temprana conquista, Del Busto (1995: 35) habla de una conspiración de los caciques que habitaban las orillas del río Chira y de los pescadores de las playas cercanas y que fue descubierta a tiempo por Pizarro, en julio de 1532, antes de la fundación de San Miguel de Tangarará. El marqués gobernador, para reprimenda de los indígenas y demás caciques, mandó que catorce de ellos fueran quemados vivos. Es probable que uno de estos jefes étnicos haya sido el del pueblo de Pariña.

No tenemos noticias de Pariña como encomienda ni quién fue su primer encomendero en esos tiempos de inicios de la Conquista. La primera noticia de la existencia de Pariña como encomienda la tenemos en la relación de los repartimientos que nos da Loredo (1958: 265-275). Allí se menciona al repartimiento de Pariña, como encomienda de Francisco de Villalobos. A éste se la había concedido Gonzalo Pizarro, en los sucesos de su rebelión contra la Corona. También le fueron adjudicados el repartimiento de Tumbes junto a un principal Mancoia [Máncora] y un principal Consegra. Todos rendían un total de 3000 pesos de tributo anual. De Máncora y Pariña, ubicadas en la costa, se servía de 200 indios. Él se encargaba de mantener a Gonzalo con buen avituallamiento y aprovisionamiento, por lo mismo que se preocupaba de enviarle a Lima mucho pescado, mandando en una ocasión «todo el pescado que pude haber de estos indios míos de Tumbes y Pariña».

Por ser Villalobos un hombre fiel y de confianza de Gonzalo Pizarro y su lugarteniente en el norte (Tumbes y Piura) era claro que iba a caer en desgracia ante los ojos del pacificador La Gasca, quien por este motivo le quitó las encomiendas que tenía señaladas.

Así su encomienda pasó a poder de Alonso Rangel quien, según Zevallos Quiñones (1994: 1516), había sido fundador de la primera Piura, ignorando qué encomienda pudo haber tenido en esos primeros tiempos. Este encomendero, como muchos de este periodo conflictivo, fue en un principio leal a Gonzalo Pizarro, pero a diferencia de Villalobos, supo cambiar estratégicamente a tiempo al bando Real, pasando a ser colaborar de Pedro de la Gasca. De esta manera, al finalizar la rebelión gonzalista y aparentemente pacificado el territorio del virreinato peruano, se hace acreedor en Guaynarima, de una renta anual de 300 pesos. En 1561, Alonso Rangel continúa como encomendero de Pariña, Máncora y Catacaos.

Alonso Rangel se casó con Beatriz Vasques, quien había estado casada en primer matrimonio con un tal Pedro de los Ríos. Debió fallecer en la década del 60 del siglo XVI. Su viuda se casó, en terceras nupcias, con un tal Gonzalo Prieto de Ávila -luego sería simplemente Dávila (ARP, Notarial Colonia: leg. 21, protoc. 2)—7. Él será por lo tanto el nuevo encomendero de Máncora y Pariña. Estando él como su encomendero, los indios de Pariña y su cacique Francisco de Pariña «el viejo», son reducidos en el pueblo San Juan del Valle de Catacaos hacia 1573. Este encomendero mantiene una gran actividad social, política y económica en la región y fuera de ella, en la que el trabajo y tributo de sus indios juegan un papel muy importante. Este encomendero muere en el año 1600.

7 Este documento contiene el testamento de Beatriz Vázques y está fechado en Piura el 6 de agosto de 1592. 
Con respecto a la reducción toledana en el pueblo de San Juan del Valle de Catacaos, incluía el doble de parcialidades que el de San Lucas de Colán. A dicho valle se redujeron no solo parcialidades repartidas por distintos lugares adyacentes al río Piura, sino también grupos provenientes del valle del río Chira, y muy cercanos al pueblo de Colán. Así, el pueblo quedó conformado por las parcialidades siguientes: Narigualá, Menón, Mecache, Mechato, Mecomo, Poechos, Amotape, Marcavelica, Tangarará, La Chira, Pariña, Sócola, Cívar y Melén. Estas tres últimas, en la segunda mitad del siglo XVII, estarán subordinadas a Narigualá, junto a otros grupos menores y cuyos nombres parecen referirse a su jefes, segunda persona, o a la actividad principal a la que se dedicaban: Mevite, Olleros, Pablos, Gonsa, Purilla, Payabe, Megualora y Apucha (ARP, Corregimientos: leg. 12, exp. 195).

Al parecer, la presencia de cacicazgos traídos a Catacaos desde el valle del Chira se debió a la actitud de los españoles y criollos ya establecidos en Piura, quienes vieron la ocasión propicia para acceder a las ricas y fértiles tierras de orillas del Chira e iniciarse unos, o continuar otros, con las actividades agrícolas y ganaderas en la región que algún beneficio mediano les iba proporcionando. En este sentido resulta muy ilustrativo encontrar al momento de la reducción toledana a Gonzalo Prieto Dávila como alcalde ordinario de la ciudad de Piura, y fue quien personalmente se encargó de guiar al visitador Bernardino de Loayza para la reducción del pueblo de Catacaos y posteriormente, en 1588 al visitador Juan de Cadalso Salazar, al momento del traslado definitivo de la ciudad de Piura a la zona del Chilcal o Tacalá (ARP, Corregimientos: leg. 14, exp. 254).

Igual motivo se puede esgrimir para explicar la presencia del grupo Poechos en el pueblo y de los grupos de cacicazgos que antes se encontraban habitando la parte del Medio y Alto Piura, quienes hasta antes de las reformas toledanas se encontraban encomendados en diferentes personas. Es el caso de los indios del valle de Dipatera (Diapatera o Yapatera, que hacia 1549 tenía a un principal llamado Cosegra8 a cargo de 100 indios), del valle de Piura (que era en ese entonces — antes de las reformas toledanas - la ubicación de Monte de los Padres actual, llamada también Piura La vieja), de Moscalaque (llamado de otro modo como valle de Moscala), Malingas, el valle de Pabor o Pabur, que servía hasta 1549 el principal Guacoma; los mismos que luego serán reubicados en otros pueblos o su población desaparecerá por diferentes motivos, quedando su nombre únicamente como denominación de las nuevas haciendas y estancias en poder de los encomenderos y otros particulares recién venidos de la península9.

Luego de producida la reducción, el panorama territorial de la zona del Alto y Medio Piura es de un paisaje muy rico en potenciales agrícolas y ganaderos, sin indios o grupos de ellos habitando el terreno, que quedaba así listo para ser beneficiado por los encomenderos o no encomenderos piuranos, quienes cuidaron —eso sí- de mantener en los pueblos reducciones, la mano de obra apropiada necesaria para sus granjerías. Aunque la mayoría de las veces estuvieron disputándose la mano de obra indígena pues la baja poblacional se fue acentuando, sin visos de recuperación, hasta fines del siglo XVII. Es importante señalar

8 Páginas atrás mencionamos a un principal Consegra como perteneciente a Francisco de Villalobos junto a otros repartimientos como Tumbes, Pariña y Mancoia. Debe tratarse del mismo principal que luego le será quitado a Villalobos —cf. Loredo (1958: 265-275)—.

9 Estos nombres de grupos, caciques y principales aparecen mencionados en Loredo (1958). Son las encomiendas existentes en San Miguel de Piura al finalizar la rebelión de Gonzalo Pizarro, es decir antes de 1549. Moscalaque figura como pueblo reducción después de las reformas toledanas, pero su ubicación en el valle de Piura lo hacía apetecible para los viejos encomenderos, hacendados y estancieros piuranos. Se va a propiciar muy pronto su despoblación y sus indios son reubicados en Sondorillo, parcialidad del pueblo de San Pedro de Huancabamba —cf. ARP (Corregimientos: leg. 9, exp. 147)—. Pabur, Moscalaque y Malingas aparecen mencionadas como encomiendas de Piura en la relación de encomiendas de 1561 que ha sido publicada por Teodoro Hampe. 
que las estancias y haciendas más importantes de fines del siglo XVI y de los dos siglos posteriores, serán Malingas, Diapatera y Pabur, cada una con subdivisiones de corrales y con gran cantidad de ganado mayor y menor.

En cuanto a la forma de tributar, los grupos de parcialidades reducidas en Catacaos tributaban en plata y en especies. En especie, los productos eran: ropa de hombre y de mujer, sogas, aves de Castilla (gallinas), huevos, maíz (que servía de alimento para las aves) y trigo (como materia prima o en forma de harina). En este sentido, una peculiaridad del grupo Pariña fue su cambio forzoso en la actividad más importante, que hasta antes de las reformas toledanas, realizaban. De ser pescadores, pasaron a partir de 1573-1574 a especializarse en labores agrícolas, ganaderas y artesanales (textiles), las mismas que les permitiera obtener el tributo necesario, olvidándose poco a poco de su actividad primigenia que había sido también la de sus ancestros prehispánicos.

Dada la diversidad de grupos reducidos en Catacaos, el acceso al cargo de cacique gobernador presentó continuos problemas y quejas por parte de los otros caciques subordinados, debido a disputas entre los originarios y forasteros, representados por los caciques de Narigualá y La Chira respectivamente y agrupando, cada uno tras de sí a los de las otras parcialidades. Estas disputas y rencillas las había vivido Sebastián y las tenía muy frescas en su memoria. Además había sido informado por sus abuelos que los pleitos no eran nuevos sino que venían de fines del siglo anterior. Un bisabuelo suyo, don Juan de La Chira, había sido centro de quejas y denuncias por parte de los demás caciques e indígenas de Catacaos, debido a su ineptitud y maldad en el ejercicio del gobierno y a su confabulación en busca de proteger sus intereses personales y el de las autoridades locales como el corregidor, cura doctrinero y encomenderos (AGI, Audiencia de Lima: 155).

Los dos grupos debieron conformarse en un principio teniendo en cuenta su origen o procedencia, pero conforme avanzó el tiempo y las relaciones económicas, sociales y políticas se fueron consolidando, las conformaciones de alianzas variaron de acuerdo a los intereses familiares (del grupo o red familiar ampliado debido a los matrimonios exogámicos entre los miembros de la élite indígena), del grupo económico o el interés también individual, muy presente en el siglo XVII.

Por esta razón no habría sido raro que don Sebastián se enfrente, en distintos momentos y situaciones, tanto a caciques de parcialidades diferentes a las de su familia, como a caciques que eran sus familiares y con los que algunas veces luchó desde el mismo bando para hacer frente a las denuncias de los otros caciques. En el primer caso estaban los pleitos que tuvo que afrontar junto a su abuelo Carlos y su tío Pablo de La Chira, enfrentándose a los caciques de las parcialidades de Narigualá, Menón y Mecache, por haber abusado de sus indios en el cobro excesivo que hacían del monto tributario que realmente debían pagar (ARP, Corregimientos: leg. 13, exp. 221). Fueron éstas las situaciones más frecuentes que le tocó afrontar, pero no por ello las más difíciles. En el segundo caso, están las rencillas que a menudo tuvo que afrontar con caciques que eran parte de su familia. Como cuando litigó en 1680 contra su tío Pablo de La Chira, por el acceso y mejor derecho a la propiedad de una huerta de frutales muy fructífera que se ubicaba en las tierras del pueblo de Catacaos (ARP, Corregimientos: leg. 14, exp. 254) y, la que según él le había dado en dote su abuelo Carlos a su madre María, al momento de contraer nupcias con su padre Francisco de Colán y Pariña, y que por lo tanto le había correspondido a él heredar a la muerte de sus padres.

Pero quizás el litigio más doloroso que tuvo que afrontar fue la demanda que le entablaron sus hermanos (tanto los de padre y madre: Diego Flores y Juana Pariña, como el de madre: Gonzalo Mecache) en 1690, acusándolo de haberse quedado con todo el dinero que 
debían heredar por partes iguales de sus padres ya difuntos, y del cual se había aprovechado Sebastián por ser el hijo mayor y de más confianza de su madre doña María de La Chira (ARP, Corregimientos: leg. 16, exp. 296).

En este caso, salta a la vista la desconfianza de los hermanos, quienes dejando de lado la solidaridad y fraternidad elevan la acusación a la autoridad del corregimiento. El cacique se defiende aduciendo que a sus hermanos menores nunca les había faltado nada. Después de la muerte de su padre primero y de su madre después, él se había preocupado personalmente de ello, poniendo incluso de sus bienes. Pero a sus hermanos no les quedaba claro esto, tenían sus dudas, por eso la demanda. Don Sebastián señalaba que de la herencia de su madre nada quedaba, pues había tenido muchas deudas que pagar, a lo que se agregó el entierro especial y lujoso que su madre merecía. Por lo que no había quedado remanente alguno, por el contrario un pequeño saldo negativo que él había cancelado de su propio peculio.

El cacique, en esos momentos finales de su existencia, había dado en unos cuantos minutos, una rápida pero detenida mirada a lo que había sido su actuación, como autoridad étnica perteneciente al aparato burocrático virreinal $y$, como personaje particular dentro de la sociedad y economía piurana de la segunda mitad del siglo XVII, remontándose incluso al siglo antecedente, de acuerdo a lo que sus padres le habían contado. Luego de esa reflexión rápida, probablemente concluyó y fue consciente que dentro de la actividad y enorme responsabilidad que tuvo ante sí, pudo haber hecho más cosas a favor de la unidad de su familia (económica y social) así como por el bienestar de los indios a él sujetos, cosa en la que nunca antes había pensado lo suficiente.

Este fue el panorama político, social y económico en el que se desenvolvieron estos señores étnicos. Uno de ellos, quien gobernó casi 30 años, Sebastián de Colán y Pariña ordena su testamento y deja todos sus bienes a los tres tesoros más importantes de su vida: su esposa y sus dos hijas, a quienes por cierto había ya casado años antes de manera muy conveniente.

Su testamento es muy rico y de un valor etnohistórico incalculable, no solo por la información que contiene sino también por ser uno de los pocos testamentos de autoridades indígenas «piuranas» de los siglos XVI y XVII encontrados hasta el momento en los diversos archivos nacionales y extranjeros.

Alcanza un mayor valor al ser cotejado y comparado con el testamento de su tío bisabuelo don Luis de Colán, ya que permite ver el proceso de evolución y consolidación de la institución cacical en un pueblo de indígenas del corregimiento de Piura, que luego, por diversos mecanismos sociales estratégicos, se va expandiendo hacia otros pueblos del mismo corregimiento. Esto a pesar de que el aspecto de prosperidad económica, que nos presenta el testamento de Luis, ya no se aprecie en Sebastián; por el contrario parece que se ha producida una pérdida en las capacidades comerciales de sus descendientes, quienes ahora, a fines del siglo XVII se orientan hacia otros rubros, en los cuales no tendrán los mismos éxitos que los caciques antiguos 10.

Finalmente, presentamos un cuadro genealógico de los señores étnicos que gobernaron el cacicazgo de Colán durante los siglos XVI y XVII (cuadro 1).

10 El autor de este artículo se encuentra en la actualidad realizando un trabajo comparativo entre los dos testamentos mencionados, en el cual ampliará estas ideas preliminares que se dan a conocer en los párrafos finales. 
Jorge Pável Elías Lequernaqué
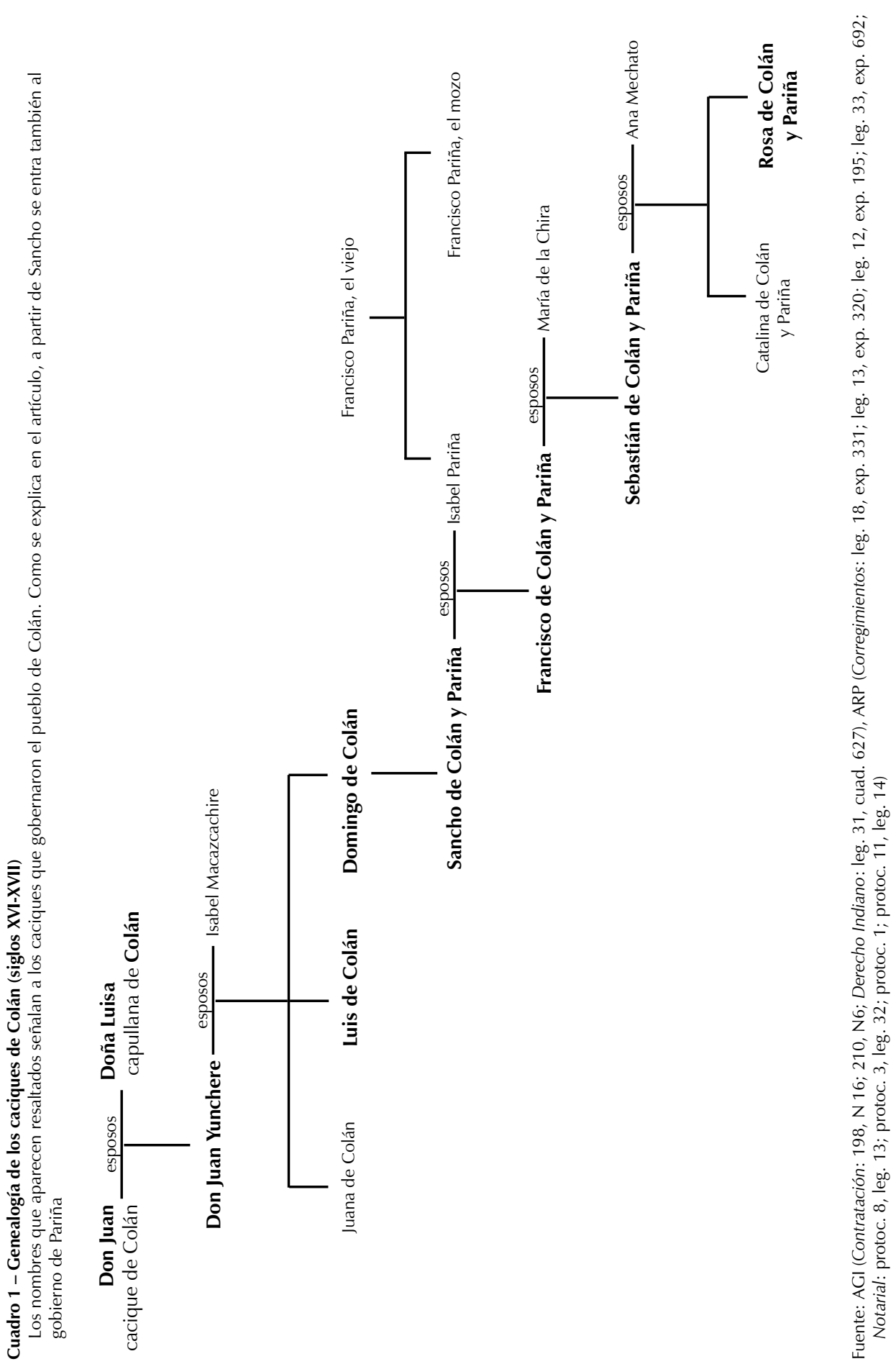


\section{Referencias citadas}

\section{Fuentes primarias}

\section{ARP (Archivo Regional de Piura)}

Serie Corregimientos, legajo 8, expediente 118. Año 1655

Serie Corregimientos, legajo 8, expediente 116. Año 1655

Serie corregimiento, legajo 9, expediente 147. Año 1662

Serie Corregimientos, legajo 12, expediente 195. Año 1670

Serie Corregimientos, legajo 12, expediente 196. Año 1671

Serie Corregimientos, legajo 13, expediente 221. Año 1673

Serie Corregimientos, legajo 14, expediente 254. Año 1680

Serie Corregimientos, legajo 16, expediente 296. Año 1690

Serie Corregimientos, legajo 18, expediente 331. Año 1695

Serie Corregimientos, legajo 33, expediente 692.

Serie Notarial Colonia, protocolo 53, folio 144v. Escribano: Francisco de Morales. Año 1602

Serie Notarial Colonia, legajo 14, protocolo 11. Escribano: Antonio de Escalante Osorio. Años 1641-1643

\section{AGN (Archivo General de la Nación. Lima)}

Derecho Indiano, legajo 31, cuaderno 627. Año 1610.

\section{AGI (Archivo General de Indias)}

Audiencia de Lima, Lima 155. Año 1624.

Contratación 198, N 16

Contratación 210, N 6. Año de 1573

\section{Fuentes secundarias}

BUSTO D., J. A. del, 1995 - Fundadores de ciudades en el Perú. Siglo XVI, 261 p.; Piura: Universidad de Piura.

LOREDO, R., 1958 - Bocetos para la nueva historia del Perú: los Repartos; Lima: D. Miranda.

ROSTWOROWSKI, M., 1982 - Testamento de don Luis de Colán, curaca en 1622. Separata de la Revista del Museo Nacional, XLVI: 507-543; Lima.

ZEVALLOS Q., J., 1995 - Los Fundadores de San Miguel de Piura; Piura: Universidad Nacional de Piura. 